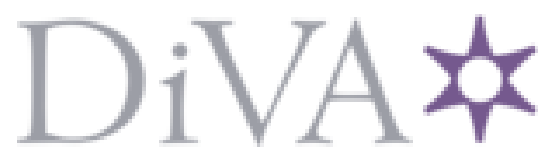

http://www.diva-portal.org

This is the published version of a paper published in Environmental Politics.

Citation for the original published paper (version of record):

Baker, S., Eckerberg, K., Zachrisson, A. (2014)

Political science and ecological restoration.

Environmental Politics, 23(3): 509-524

http://dx.doi.org/10.1080/09644016.2013.835201

Access to the published version may require subscription.

N.B. When citing this work, cite the original published paper.

Permanent link to this version:

http://urn.kb.se/resolve?urn=urn:nbn:se:umu:diva-83954 
This article was downloaded by: [Umeå University Library]

On: 28 May 2014, At: 07:13

Publisher: Routledge

Informa Ltd Registered in England and Wales Registered Number: 1072954 Registered office: Mortimer House, 37-41 Mortimer Street, London W1T 3J H, UK

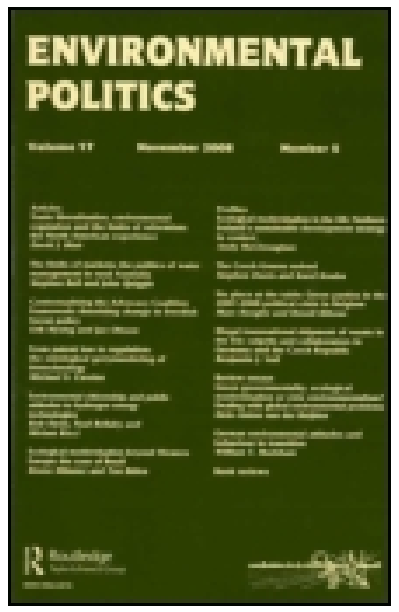

\title{
Environmental Politics
}

Publication details, including instructions for authors and subscription information:

http:/ / www. tandfonline.com/loi/ fenp20

\section{Political science and ecological restoration}

\author{
Susan Baker ${ }^{a}$, Katarina Eckerberg ${ }^{b} \&$ Anna Zachrisson ${ }^{b}$ \\ a Cardiff School of Social Sciences, Cardiff University, \\ Wales, UK \\ b Department of Political Science, Umeå University, \\ Sweden \\ Published online: 11 Oct 2013.
}

To cite this article: Susan Baker, Katarina Eckerberg \& Anna Zachrisson (2014) Political science and ecological restoration, Environmental Politics, 23:3, 509-524, DOI: 10.1080/ 09644016.2013.835201

To link to this article: http:// dx. doi.org/ 10.1080/09644016.2013.835201

\section{PLEASE SCROLL DOWN FOR ARTICLE}

Taylor \& Francis makes every effort to ensure the accuracy of all the information (the "Content") contained in the publications on our platform. Taylor \& Francis, our agents, and our licensors make no representations or warranties whatsoever as to the accuracy, completeness, or suitability for any purpose of the Content. Versions of published Taylor \& Francis and Routledge Open articles and Taylor \& Francis and Routledge Open Select articles posted to institutional or subject repositories or any other third-party website are without warranty from Taylor \& Francis of any kind, either expressed or implied, including, but not limited to, warranties of merchantability, fitness for a particular purpose, or non-infringement. Any opinions and views expressed in this article are the opinions and views of the authors, and are not the views of or endorsed by Taylor \& Francis. The accuracy of the Content should not be relied upon and should be independently verified with primary sources of information. Taylor \& Francis shall not be liable for any losses, actions, claims, proceedings, demands, costs, expenses, damages, and other liabilities whatsoever or howsoever caused arising directly or indirectly in connection with, in relation to or arising out of the use of the Content. 
This article may be used for research, teaching, and private study purposes. Terms \& Conditions of access and use can be found at http:// www.tandfonline.com/page/terms-and-conditions

It is essential that you check the license status of any given Open and Open Select article to confirm conditions of access and use. 


\title{
Political science and ecological restoration
}

\author{
Susan Baker $^{\mathrm{a} *}$, Katarina Eckerberg ${ }^{\mathrm{b}}$ and Anna Zachrisson ${ }^{\mathrm{b}}$ \\ ${ }^{a}$ Cardiff School of Social Sciences, Cardiff University, Wales, UK; ${ }^{b}$ Department \\ of Political Science, Umeå University, Sweden
}

\begin{abstract}
Ecological restoration has taken on a new significance in the face of climate change and biodiversity loss. Despite its growing policy salience, however, the social and political sciences have paid limited attention to the study of ecological restoration policy and practice. By drawing upon the political science study of multilevel governance, institutions, power relations, and place-based politics, a flavour is given of what a political science engagement might contribute to the rich tapestry of analysis that has already been produced by other disciplines on ecological restoration. As the use of restoration grows, it is increasingly likely that it will give rise to social dispute and be brought into conflict with a variety of environmental, cultural, economic, and community interests. Restoration policy and projects encounter professional and institutional norms as well as place-specific interests and values. There is urgent need to investigate how and in what ways some interests become winners and others losers in these activities, and how this in turn can influence ecological restoration outcomes. A political science lens could help build new criteria for evaluating the success of ecological restoration, ones that combine both process- and product-driven considerations.
\end{abstract}

Keywords: value of restored nature; policy perspective; institutional setting; interest politics; social conflicts; place specificity

\section{Introduction}

Ecological restoration can be understood as 'the process of assisting the recovery of an ecosystem that has been degraded, damaged, or destroyed' (SER 2004). Several political actors, including states and international organisations such as the United Nations Environment Program (UNEP), have made declaratory commitment to engage in ecological restoration as a means of addressing global environmental change (Nellemann and Corcoran 2010). Climate change mitigation and adaptation policy is increasingly relying upon restoration, e.g. through reforestation for carbon sequestration or restoring wetlands for flood protection. There is also emphasis on the importance of restoration for achieving the 2020 Biodiversity Targets, the so-called Aichi Targets, including by the European

\footnotetext{
*Corresponding author. Email: Bakerscm@cardiff.ac.uk original work is properly attributed, cited, and is not altered, transformed, or built upon in any way, is permitted. The moral rights of the named author(s) have been asserted.
} 
Union (EU). Furthermore, it is in increased use as a compensation tool in planning decisions and as a tool for addressing environmental damage from industrialisation, mining, and quarrying as seen, for example, in Germany where an ambitious programme of ecological restoration and remediation was undertaken in the new Länder following reunification.

Despite its growing policy salience, ecological restoration as such is not new, and the idea of helping land recover from the effects of human use dates back at least to biblical times, in the fallowing of land. Active rehabilitation was also common in reforestation efforts in the Middle Ages in Western Europe, and was evident in practices of game management and forestry in nineteenth-century Europe (Jordan 2000, p. 23). In the contemporary period, restoration is being used in more diverse ways and for the purposes of higher-scale policy objectives. Restoration is increasingly driven by the need to restore ecological functions and to ensure ecosystem service delivery in the context of global environmental change. As a result, an intensification of both government and corporate engagement in restoration initiatives can be expected.

While the social and political sciences have paid limited attention to the study of ecological restoration, this contrasts with humanities, in particular the disciplines of philosophy, social anthropology, and history, which have made considerable strides in their respective studies (Attfield 1994, Gobster and Hull 2000, Egan et al. 2011). In this paper, we address this deficit, arguing for a political science engagement. Ecological restoration needs, like all political initiatives, to be subject to investigation in the light of the politics of policy, a politics that bring negotiations over trade-offs between competing objectives and different constituencies, and which take place in the context of the need to distribute scarce resources among diverse societal spheres (Meadowcroft 2009, p. 335). By drawing upon policy analysis, and including the political science study of multilevel governance, institutions, interests, and power relations, the paper gives an indication of what a political science engagement might contribute to the rich tapestry of analysis that has already been produced by other disciplines on restoration. We begin by outlining the nature of restoration in policy practice, providing a critical view of the key differences of opinion that can be found within the existing literature, as well as examples of actions. The next section details what a political science perspective brings to the study, ranging from the investigation of international and national governance to local and place-based politics. We conclude by discussing why political science should pay more attention to developing a critical investigation of restoration policy and practice.

\section{Ecological restoration values and practice}

A range of policy initiatives and projects can be labelled 'restoration', despite having different rationales stemming from diverse political, economic, and administrative practices, as discussed below. Restoration projects can target 
many different ecological systems or landscapes and be conducted both in urban (Platt 2006) and in rural areas. In urban areas, restoring to a certain reference point is difficult, but there are a number of restoration projects that seek to take account of both the natural and historical legacies of such sites while integrating them into plans for future use (Westphal et al. 2010). In addition, restoration activities can occur across a variety of scales, from limited and highly localised experiments, to remediation of industrial, quarrying, or mining sites, to what are best described as 'mega projects', such as the Kissimmee River restoration initiative in central Florida, restoration of the prairies in the United States, or contemporary water management initiatives in the Netherlands. It may include returning specific types of damaged ecosystems to a more 'natural' state or even creating ecosystems de novo (Hall 2010). It can also involve the deliberate reintroduction of species that have been lost at the local level due to changes in land use and other development pressures. Wolf reintroduction policies provide a typical example, and have led to controversies between ecologists and farmers in the eastern Germany, Scandinavia, and North America (Gross 2008; see also Keulartz 2009). River restoration is another focus of project attention, involving the removal of dams, river re-meandering and re-bouldering (e.g., in Sweden, see Lejon et al. 2009), 'daylighting' of culvert rivers, or ecological remediation of urban riverbanks (e.g., in the UK, see Eden and Tunstall 2006). River restoration has grasped the attention of the academic community because it is seen as indicative of a more positive relationship with our natural surroundings, heralding a move from earlier 'hard' engineering, e.g. the burial of rivers within subterranean pipes with underwater outfalls, to a newer, more environmentally sensitive approach that uses softer engineering styles and materials to integrates rivers with their floodplains (Van der Heijden 2005, Buijs 2009). Restoration has also caught the attention of researchers interested in how and to what extent the planning system has ensured that projects have been subject to sufficient public consultation (Eden and Tunstall 2006).

Given the diversity of types and complexity of activities associated with ecological restoration, it could be conceptualised as ranging along a continuum from, at one end, the construction of 'engineered landscapes', through to attempts to reintroduce some complex assemblages of species and ranging to attempts to 're-wild' a particular landscape, where human intervention kick-starts recovery then leaves natural processes free to take effect. These different understanding of restoration can be seen as linked to different 'metaphorical frames' containing different terms or metaphors about restoration which, in turn, call for different management practices (Keulartz and van der Weele 2008). This can be seen, for example, in the restoration metaphors typical of traditional conservation practices that speak about 'native' and 'non-native' species, with the normative implication that the former can be seen as 'desirable', whereas non-native species are 'undesirable' elements of the system that need to be removed (Keulartz and van der Weele 2008). However, we are also mindful of the pitfalls of adopting too wide a definition of ecological restoration, as this may result in the "value 
added' of restoration being lost or confused within a host of other social, environmental, or cultural initiatives (Bradshaw 1995, Burger 2008). In the next section, attention is paid to how different restoration values connect to policy practice.

\section{The value of restored nature}

Given both its range and scope, it is not surprising to find that there are longrunning disputes about what restoration is attempting to accomplish, to what end, and how both the act of restoration and the 'product' of restoration are to be valued (Gobster and Hull 2000). Early attempts to value ecological restoration judged the success of a project using three specific technical performance criteria: structural replication, rooted in the notion of, or attempts to obtain ecological fidelity; functional success, where biogeochemical processes operate according to expectation of the specific ecosystem; and durability in the restored ecosystem, a characteristic that is dependent on subsequent management strategies (Higgs 2003, pp. 128-129; see also Higgs 1997). This presents a 'product-orientated' view, primarily targeting the outcome of restoration efforts. More recently, the promotion of resilience, in particular in the context of climate change, is considered an important criterion of success (Dunwiddie et al. 2009). However, this raises the spectre of a shift from a 'historic' notion rooted in fidelity to a 'futuristic' approach to restoration (Choi 2007, Thompson and Benik-Keymer 2012), including the creation of synthetic systems to achieve ecological, social, and economic goals (Palmer et al. 2004, Martinez and Lopez-Barrera 2008).

The 'product-orientated' view has been criticised for denying or even restricting the 'restorative' capacity of ecological restoration. This focuses upon the capacity of restoration projects to provide a means whereby local communities can reconnect with nature and how this can enable society to make 'restitution' for past environmental damage (Cowell 1993, Higgs 1997). This understanding shifts attention away from narrow 'product' orientalised notions of 'success' to consideration of the processes involved in restoration and how they facilitate or restricts participatory engagement (Higgs 1997). The process focus opens up an opportunity for political science engagement, in particular in relation to the openness of the policy process and the style of policy steering.

These considerations also bring our discussion to a very different outlook, wherein ecological restoration is viewed as a deeply anthropocentric and morally questionable endeavour. For Katz in particular, the belief that restoration activities can replace natural value by the creation of functionally equivalent natural systems is an expression of human hubris regarding technical power and human capacity to master the natural world (Katz 2000, p. 38). Restored sites are criticised for their lack of authenticity, interruption of historical continuity, and change of origin (Elliot 1982). Compensatory restoration, such as the creation of de novo wetlands for compensatory planning purposes, denies the place based 
and place connectivity of a particular site. Furthermore, such activities are seen as part of the increased humanisation of the natural world, as such sites require continuing management interventions (Katz 2000, pp. 30-38; see Attfield 1994 for an excellent overview of this dispute).

This section has provided an introduction to the complex issue of defining what ecological restoration means and also given a flavour of the debates that exist within the existing literature on the nature of, and value attributable to, ecological restoration. In the next section, we present a political science view on ecological restoration.

\section{The politics of ecological restoration}

Why should political scientists analyse restoration, and what can a political science perspective bring to this study? Exploring the politics associated with restoration, as it ranges from the international to the national, local, place-based levels, is addressed in relation to both restoration policy as well as projects.

\section{From international commitments to national policy engagement}

Several political actors, including states and international organisations, have made declaratory commitment to engage in ecological restoration. In particular, the Aichi Target 15 lays down that 'By 2020, ecosystem resilience and the contribution of biodiversity to carbon stocks has been enhanced, through conservation and restoration, including restoration of at least 15 per cent of degraded ecosystems, thereby contributing to climate change mitigation and adaptation and to combating desertification' (CBD 2010). Similarly, the European Union (EU) Biodiversity Strategy sets its Target 2 that by 2020, ecosystems and their services are maintained and enhanced by establishing green infrastructure and restoring at least $15 \%$ of degraded ecosystems (CEC 2011). Restoration also forms part of various resource-specific policies, e.g. the EU Water Framework Directive, whose target is to restore surface waters and ground waters to 'good ecological status' (EC 2000). As a tool for addressing global environmental change, restoration has become embedded in the play of political power as it is acted out through the processes of negotiating on, and subsequent delivering of restoration promises. As such, research is needed into how and with what consequences the declaratory commitment to restoration is delivered in practice, particularly at the sub-national, regional, and local levels, where implementation of policy typically takes place. It also brings attention to the need to investigate the potential for and barriers to implementation of restoration practices, and how these operate across different governance scale and sociopolitical contexts.

The importance of, for example, different historic legacies in shaping how restoration policy is pursued is apparent when comparing the situation in the United States and Europe. In the United States, the pursuit of 're-wilding' (Swart 
et al. 2001) approaches have been more dominant, due to the fact that Western exploitation (both agricultural and industrial) started relatively late in the United States compared to Europe, making 'restoration' towards a pre-settlement state more readily strived for than in the European case (Hall 2010). In effect, the United States exemplifies what have been described as the two most 'rigorous' models of restoration (those that make most reliance upon historical, baseline conditions) as well as the weakest model (rehabilitation, e.g. of industrial sites, where 're-naturalisation' is restricted both by the severity of the site degradation and contamination). In contrast, German examples fit more comfortably into the middle range of models, namely the habitat model and the cultural landscape model (Westphal et al. 2010). While this and other such models provides a useful tool for comparative analysis, most of the models available within the literature structure ecological restoration primarily according to the underlying values that are attached to restored nature. A political science perspective will add to this by exploring other rationales and drivers stemming, e.g. from policy choices and institutional factors.

Thus, for example, in the United States in particular, restoration often takes place to satisfy conditions laid down by planning permits, which mandate compensatory mitigation when there are adverse environmental impacts from particular development projects (Robertson 2000). Some may argue that this is not in fact restoration because no site is restored as such. However, restoration through a required mitigation program is common practice, especially for wetlands, making restoration practices deeply embedded in legal regulations and planning processes. The US policy of 'no net loss' of wetlands is an important driver and sees developers creating new wetlands so as to mitigate their destruction elsewhere. A similar example is provided by the Bothnia Railway development in Sweden, where mitigation restoration was eventually approved by the European Commission to compensate for the biotope damage caused by the railway being built through a Natura 2000 area in the Ume River delta, in Northern Sweden (McGillivray 2012). Used as a compensatory planning tool, restoration can underpin economic development priorities and act as a source of profitable business. It has led, for example, to the development of wetlands mitigation banking (WMB) in the United States. In WMB, a 'bank' of wetlands habitat is created, restored, or preserved and then made available to developers who must 'buy' habitat mitigation as a condition of planning approval. This mechanism is in the process of being extended to other settings, including watershed protection. The shift in emphasis from prescriptive regulation to trading, as witnessed by the use for market instruments such as WBM, provides a particularly useful case study for comparing the use of regulatory and market instruments for environmental protection under restoration (see Salzman and Ruhl 2005). Whether and to what extent restoration in Europe is driven by similar economic rationale as that found in the United States remains unclear. The relative weight given to more direct 'environmental' criteria, in particular those associated with implementation of the EU Water Framework Directive and 
of the Natura 2000 programme and more recently climate change and biodiversity policy and targets, may suggest otherwise. In Europe, despite differences within and between member states, there is consensus that environmental protection cannot be left to market forces and that environmental protection is a legitimate goal of government (Krämer 2002, p. 15). This European political culture makes it more likely that restoration projects will emerge from the need to fulfil more direct environmental objectives and goals.

As mentioned, the EU's use of restoration targets for meeting its international biodiversity commitments up to 2020 (CEC 2010) shows that restoration has become an important policy tool. Investigation is now needed into whether the political will to deliver on the declaratory commitment to restoration is present, at what government levels, and whether the capacity, including financial resources, is available to implement this commitment, as reflected in the delivery of restoration initiatives and projects. In other words, we need to explore the plight of restoration once it becomes embedded in negotiations between different interest groups operating at lower scales and as this policy takes its place amongst the host of competing policy objectives that typically crowd the policy terrain. Answering these questions requires detailed empirical investigation, but these need to be informed by a framework that goes beyond the mere focus on institutional capacity.

\section{The institutional context}

Institutional approaches within political science are increasingly drawing upon discursive elements, where institutions become 'simultaneously constraining structures and enabling constructs of meaning' (Schmidt 2010, p. 4). This brings our attention to the need to examine how restoration policy enters into the policy arena, bringing with it a new optimism about the promises of restoration in managing the problem of global environmental change. Why, how, where, and when do certain notions of restoration gain ground among decision makers and/ or the public?

The commitment to making enhanced use of restoration operates through interactive policy processes within an institutional context. Institutions can be seen as formal or informal procedures, routines, norms, and conventions embedded within organisational structures that may distribute power unevenly among interest groups (Hall and Taylor 1996, p. 938). Viewed from an institutional perspective, the resulting power relations structure negotiations on restoration, and thus decisions about what types of restoration projects are to be implemented and where. The professional norms and knowledge claims held by implementing agencies and that shape such decision making should also be investigated with this analytical lens. Professional norms among those institutions dealing with the management of the natural environment, including landscape management, may differ from one profession to another, as for example, between forest ecologists, landscape architects, and city and 
regional planners, as shaped by their respective disciplines. For example, it has been suggested that wilderness approaches to restoration best fit to hierarchical steering, as opposed to participatory practices, because the preferred type of nature is largely formulated and legitimised by experts, mostly ecologists (Swart et al. 2001). These norms, in turn, may well be very different from those held by voluntary practitioners and community groups involved in restoration activities at the place-specific level. For example, conservation groups and governmental agencies holding to traditional conservation practices apply a strict dichotomy between native and non-native species, a stance that can conflict with the norms held by voluntary practitioners and community groups involved in restoration activities at the placespecific level (Keulartz and van der Weele 2008). This, in turn, can lead to alienation of community practitioners from restoration projects.

Institutions are perceived to be relatively persistent and thus as pushing development along a set of given 'paths'. Path dependence means that policy actions, such as a decision to start a restoration project, are mediated by the institutional features of a given situation, features that are often inherited from the past. Past policies thus influence any new policy decisions (Hall and Taylor 1996, p. 941). As such, policy approaches can be seen to be anchored in tradition and history (Fischer 2009). Such factors can explain why the main drivers for restoration (as least as far as our empirical evidence suggests) are different in the United States from in the EU.

\section{Social disputes and divergent interests}

As the use of restoration grows, it is increasingly likely that it will become the subject of social dispute. However, the significance of divergent anthropocentric and bio- or ecocentric positions for shaping the politics of restoration, including its potential to act as a source of social conflict, has been given limited attention. The analysis by Keulartz of the different metaphors that stakeholder groups employ in relation to ecological restoration casts some light on this issue. The use, for example, of military metaphors, such as 'war', 'invasion', and 'aliens' to refer to species that do not 'belong' to a particular environment, may intensify controversies, making it easy to see opponents as 'enemies' one needs to fight (Keulartz 2007, see also Keulartz and van der Weele 2008). But emerging conflicts can be explained by other factors, including different goals, values, and interests among the various agencies and practitioners. In specific placebased restoration activities, social conflicts could also involve deep emotions and attachments among those concerned, as discussed below. Such conflicts also concern power relations between implementing agencies and among local communities.

Looking across temporal scales, research should also consider whether the needs of future generations or of present generations are prioritised, while the investigation of spatial scale requires consideration of the divergent needs of the 
North or South, the national, or the local level in policy decisions. Global climate agreements in the post-2012 period, for example, are likely to include actions to reduce emissions caused by deforestation and degradation (REDD and REDD+) through regeneration of native forests and expanding tree plantation schemes. These restoration initiatives run the risk, however, of shifting deforestation from high-biomass forests, such as rainforests, to low-biomass native ecosystems, such as savannahs and grasslands, or may result in the replacement of native ecosystems by tree plantation. Such actions can threaten local cultures and livelihoods and may also bring conflict with environmentalists concerned with wildlife protection (Stickler et al. 2009). This brings us to matters of 'environmental justice', i.e. to the equitable treatment and involvement of all social groups in the development, implementation, and enforcement of restoration laws, regulations, policies, and initiatives. It involves investigation of the political and social interactions through which restoration goals are determined and revised, collective decisions are enforced, and resources allocated. Only then can judgement as to the democratic legitimacy of restoration, including at the project level, be made.

Furthermore, research has failed, as yet, to investigate whether restoration can in fact help promote the social dimensions of resilience in the face of climate change. It may well be the case that some form of ecological engineering, involving the design, construction, and management of ecosystems that goes well beyond current restoration practices, may be needed to keep pace with climate change. This says nothing about society's ability to adapt to these synthetic systems, including from cultural and psychological perspectives. The growing reliance upon restoration to make amends for environmental destruction and to correct for the loss of ecosystem functionality and related ecosystem services also runs the risk that restoration policy will promote a moral hazard, i.e. it may incentivise us to continue to engage in environmentally destructive activities in the belief that restoration initiatives can fix such problems later. Thus used, restoration may come to weaken policy and indeed even individual resolve to address environmental problems at source. A meta-analysis of restoration initiative, which showed that at best ecological restoration has increased the provision of biodiversity and ecosystems services by $44 \%$ and $25 \%$ respectively and that the value of both remained lower in restored versus intact reference ecosystems, provides a sobering reminder of the risks involved in over-reliance upon restoration as a policy tool to address global environmental change (Benayas et al. 2009).

\section{Potential for participation}

Successful implementation of restoration projects typically depends upon achieving co-operation between actors operating in both the public and private spheres and that may hold different and not necessarily compatible interests (Gross 2006). Typically, a restoration project will orbit the interests of 
landowners, landscape ecologists, local authorities, economic stakeholders such as tourism interests, environmentalists, and local resource users such as farmers and anglers. The Vindel River restoration in Northern Sweden, for example, involved interests from the state forestry company, Sveaskog, the Ume and Vindel Rivers Water Council, Swedish Board of Fisheries and Swedish Environmental Protection Agency, landowners, fishery organisations, and local community groups (Vindel River Life 2010).

There are several arguments in support of the benefits of participation for the success of ecological restoration as both a policy and a practice. From an instrumental point of view, participation of non-state actors can improve the knowledge base for decision making and create more effective implementation outcomes. Participatory processes facilitate negotiation between competing interests, allowing them to accommodate each other's values and to engage in a process of learning (Gross and Hoffmann-Riem 2005). Participation can also contribute to the legitimacy of policy, thereby helping to reduce the risk of conflict over project priorities, decisions, and outcomes. Social acceptance of restoration efforts can help ensure ongoing commitment to, rather than subsequent neglect of, restoration efforts (Gobster and Barro 2000, p. 186). In addition, not only can participation be seen as a means of building understanding and commitment for collective policymaking (Dobson 2007), it can also be seen as an end in itself, i.e. as an alternative to lives centred on material consumption (Kemp and Parto 2005, p. 16). Some have described this as a potential of restoration to promote 'emancipatory egalitarianism' (Light and Higgs 1996). Thus, rather than consuming nature, through high impact, expensive 'leisure' activities, engagement in restoration projects can provide an alternative space for low impact, non-consumptive engagements with nature (Jordan 2000, p. 33). However, while participation is seen in a very positive light within the restoration literature, when viewed from a political science lens, we become mindful of the fact that the capacity for participatory processes to provide a meaningful forum for deliberations is also heavily dependent upon several variables. These include the type of formal access to policymaking that is given; the stage in the policymaking process in which participation is allowed; the 'opportunity structures' that exist within the policy process to influence policymaking; and the institutional constraints that are placed both on them and that are present more generally (Hallstrom 2004).

The potential for ecological restoration to become an arena for democratic and ecological engagement can also be restricted by other factors, particular given that restoration projects may stem from different underlying rationales. Restoration undertaken to comply with planning permits for development, as in the United States, are more often associated with privatised and profitable forms of economic activity. In short, different motivations for restoration bring with them different participatory potentials. This reiterates the point that ecological restoration also needs to be understood not only as a technical task but as deeply embedded in social and political processes. 


\section{Place specificity and attachments}

In its practical form, restoration is a place-specific activity that involves the use of a landscape or a physical feature, such as a river or bay or wetland, for a particular purpose. This means that it encounters place-specific politics (Drenthen 2009). Place use is subject to multiple priorities, which are often very difficult to reconcile. Restoration of the Australian Murray-Darling river system, for example, has given rise to conflict between farmers wishing to use the river for agriculture and the wish of conservation engineers to restore the 'natural' river flow, especially for water management and for the purposes of flood defence (Pincock 2010). While this case can be seen as typical of the classic conflicts between economic and environmental interests, conflicts can also be less clear-cut. The use of restoration for the maintenance of ecosystem services for human need can, for example, conflict with the preservation of biodiversity for its own sake. Restoration initiatives can come into conflict with other environmental interests on the policy agenda, such as supporting the growth of bioenergy crops or providing certain benefits to local communities. For example, attempts to restore lost prairie habitats in the Mid-Western United States incurred opposition at the local level because it involved destruction of local non-native woodlands to which local communities had become attached, and that ultimately saw restoration efforts blocked by court rulings (Helford 2000). The fact that views of nature are inherently linked to and help construct identity and culture explains why such conflicts often arise over restoration projects.

There is increasing interest from political scientists on the role of emotions in politics, where social spaces can then be thought of as emotional landscapes (Goersdorf 2006, Fischer 2009). People's views on restoration are, as already pointed out, affected by place attachments based on sometimes very strong emotions. While it is acknowledged that acceptance is more forthcoming if restoration projects build upon strong emotional or cultural attachments to place, place attachment can itself be multifaceted. Many people can be attached to a place which may be expressed in diverse and even contradictory ways. Often place attachment is related to how people, or social groups, use or experience the place, be it for leisure, commercial purposes, or religious and cultural sacredness. This all affects social attitudes towards restoration and the willingness of different groups to take part in specific projects. In addition, different users will have different expectations about what is to be restored and how it can underpin their continued use of the place. For example, they might want picturesque planting, or paths, or want a particular type of landscape to be restored to a certain state. Thus, successful ecological restoration requires understanding of and respect for the 'place' to which people have attachments (Ryan 2000, p. 224), but such approaches may prove very difficult to realise in practice.

\section{Whither nature?}

Restored sites often represent 'islands of nature' in an environment dominated by human constructions, particularly in urban settings. Planners and environmental 
managers but also activists and academic researchers have little understanding of the relationship between these 'islands' and the larger 'nature' and natural system (Vining et al. 2000, p. 158). In urban restoration initiatives, there is also a need to address social concerns, as is evident by the case of river restoration in England, where in one case in particular, the restoration of a wildlife corridor along a riverbank was heavily criticised at the local level for opening up a corridor of crime between two hitherto physically separated and socially segregated innercity housing estates (Eden and Tunstall 2006).

Yet, the social potential of restoration remains strong. This is because it may be easier to get local people involved in restoration projects - as opposed to committing to more abstract principles such as the promotion of sustainable development as those projects are content specific, local in focus, pragmatic, and immediate. The advantage from a community and social capital perspective is that restoration projects can be organised around communal activities to address communal concerns. It addition, such engagement can heighten environmental consciousness (Jordan 1994) and support the development of positive relationships between local communities and nature (Light and Higgs 1996, p. 236). We would thus argue that restoration has the potential to contribute towards the pursuit of sustainable development, although as yet we do not fully understand the conditions necessary to realise this potential at both the project and policy levels.

\section{Conclusion}

We have argued for the value of a political science investigation of restoration, not least because restoration has become part of the discourse of contemporary environmental management at the global level, has taken on policy salience through its use for meeting international commitments to address environmental change, and is increasingly used to support the implementation of specific legislation. As such, restoration is already embedded in murky and complex interest politics, wielded within particular institutional settings, policy cultures, and administrative processes and procedures. Using a political science lens to investigate restoration processes and outcomes will reveal new insights into how and in what ways the policymaking process systems shape which interests become winners and which losers in restoration initiatives. Such investigation also has to consider that declaratory commitment has to lend itself to policy action, and this involves negotiations as structured by power relations. As the use of restoration grows, it is likely that restoration will become the subject of protest, which may well divide ecological and community groups both internally and against each other. There are many fault lines opening up here: between the use of restoration for both mitigation and adaptation to climate change, while at the same time to use this as a tool to address both biodiversity loss and the restoration of ecological functions of direct interest to people. Furthermore, deeper involvement of international agencies, government, and corporate interests is likely to occur alongside voluntary, community engagement in restoration 
initiatives. This may bring restoration initiatives into conflict with a varied set of environmental, cultural, economic, and community interests.

However, restoration is also a place specific activity that encounters placespecific interests and values. In this context, implementation of restoration projects not only has to address the need for integration at the professional level, but also bridge the gaps between the different communities, be they scientific, policy, and local involved in restoration on the ground (Gross 2002). This reminds us of the importance of both institutional norms and participatory practices in shaping restoration outcomes. Our concern here is to ensure that we fully understand whether, to what extent, and how the promise of restoration can be delivered in practice, not least because the consequences of failure are high (Baker 2012). This lens will also help build new criteria for evaluating the success of restoration, and thus enable us to combine both process and product-driven considerations when judging the success of restoration outcomes.

We have indicated how to build upon restoration research from across other disciplines to take forward the political science perspective and what that might entail. We have also shown what a political science lens can contribute to understanding restoration policy and practice. This discussion has, we hope, provided sound arguments in support of the need for political science to develop further a critical perspective on restoration that is driven, in turn, by enhanced empirical engagement with the subject. As such, we make both a plea for more research while also providing an indicative exploration of ways in which that research might take place. Of course, while we have investigated what questions a political science approach may bring, we are mindful of the need to address restoration through interdisciplinary studies across the social and natural sciences (Lowe et al. 2009). However, without knowing what one's own discipline can bring to the table, it will be difficult to contribute to such collaborative research engagements. Failure to develop political science knowledge would be a lost opportunity both for political science as a discipline as well as for those committed to critical and interdisciplinary engagement with the task of promoting a more sustainable future.

\section{Acknowledgements}

This research was funded by the Swedish Research Council for Environment, Agricultural Sciences and Spatial Planning, Formas, Umea University and the Swedish University of Agricultural Science, for the project 'Ecosystem restoration in policy and practice: restore, develop, adapt' (RESTORE), Grant number 2009-450 http://www.restore-project.org. We are grateful to members of the RESTORE project team and to colleagues from Umea University for their comments on earlier drafts of this paper.

\section{References}

Attfield, R., 1994. Rehabilitating nature and making nature habitable. Royal Institute of Philosophy Supplement, 36, 45-57. 
Baker, S., 2012. From knowing to acting: ecological restoration in theory and practice, seminar, royal academy of agriculture and forestry. Facing the future - Biodiversity, ecology and economy: three pillars in future agriculture and forestry practice? Stockholm, 23 March 2012.

Benayas, J.R., et al., 2009. Enhancement of biodiversity and ecosystem services by ecological restoration: a meta-analysis. Science, 325 (5944), 1121-1124.

Bradshaw, A.D., 1995. Underlying principles of restoration. Canadian Journal of Fish Aquatic Science, 53 (Suppl 1), 3-9.

Buijs, A.E., 2009. Public support for river restoration: a mixed method study into local residents' support for and framing of river management and ecological restoration in the Dutch floodplains. Journal of Environmental Management, 90 (8), 2680-2689.

Burger, J., 2008. Environmental management: Integrating ecological evaluation, remediation, restoration, natural resource damage assessment and long-term stewardship on contaminated lands. Science of the Total Environment, 400 (1-3), 6-19.

CBD, 2010. Strategic plan for biodiversity. Available from: http://www.cbd.int/sp [Accessed 19 February 2013].

CEC, 2011. Our life insure, our natural capital: an EU biodiversity strategy to $2020 \mathrm{COM}$ (2011) 244, final. Available from: http://biodiversity.europa.eu/policy/eu-biodiversitystrategy/target-1-and-related-aichi-targets [Accessed 14 June 2012].

Choi, Y.D., 2007. Restoration ecology to the futures: a call for a new paradigm. Restoration Ecology, 15 (2), 351-353.

Commission of the European Communities (CEC) 2011, Our life insurance, our natural capital: an EU biodiversity Strategy to 2020 (Brussels, CEC, COM(2011 244 final)

Cowell, M., 1993. Ecological restoration and environmental ethics. Environmental Ethics, $15,19-32$.

Dobson, A., 2007. Environmental citizenship: towards sustainable development. Sustainable Development, 15 (5), 276-285.

Drenthen, M., 2009. Ecological restoration and place attachment: emplacing non-places. Environmental Values, 18, 285-312.

Dunwiddie, P.W., et al., 2009. Rethinking conservation practice in light of climate change. Ecological Restoration, 27 (3), 320-329.

EC, 2000. Directive 2000/60/EC of the European parliament and of the council establishing a framework for the Community action in the field of water policy. Official Journal EC2000/60.

Eden, S. and Tunstall, S., 2006. Ecological versus social restoration: how urban river restoration challenges but also fails to challenge the science-policy nexus in the United Kingdom. Environment and Planning C: Government and Policy, 2, 661-680.

Egan, D., Hjerpe, E.E., and Abrams, J., eds., 2011. Human dimensions of ecological restoration: integrating science, nature, and culture. Washington, DC: Island Press.

Elliot, R., 1982. Faking nature. Inquiry: An Interdisciplinary Journal of Philosophy, $25,81-93$.

Fischer, F., 2009. Democracy and expertise: reorienting policy inquiry. New York: Oxford University Press.

Gobster, P.H. and Barro, S.C., 2000. Negotiating nature: making restoration happen in an urban park context. In: P.H. Gobster and R. Bruce Hull, eds. Restoring nature: perspectives from the social sciences and humanities. Washington, DC: Island Press, 185-208.

Gobster, P.H. and Hull, R.B., eds., 2000. Restoring nature: perspectives from the social sciences and humanities. Washington, DC: Island Press.

Goersdorf, A., 2006. Inside deliberative experiments: dynamics of subjectivity in science policy deliberations. Policy and Society, 25 (2), 177-206. 
Gross, M., 2002. New natures and old sciences: hand-on practice and academic research in ecological restorations. Science Studies, 2, 17-35.

Gross, M., 2006. Beyond expertise: ecological science and the making of socially robust restoration strategies. Journal for Nature Conservation, 14, 172-179.

Gross, M., 2008. Return of the wolf: ecological restoration and the deliberate inclusion of the unexpected. Environmental Politics, 17 (1), 115-120.

Gross, M. and Hoffmann-Riem, H., 2005. Ecological restoration as a real-world experiment: designing robust implementation strategies in an urban environment. Public Understanding of Science, 14, 269-284.

Hall, M., 2010. Introduction: tempo and mode in restoration. In: M. Hall, ed. Restoration and history - the search for a usable environmental past. New York: Routledge, $1-12$.

Hall, P.A. and Taylor, R.C.R., 1996. Political science and the three new institutionalisms. Political Studies, XLIV, 936-957.

Hallstrom, L.K., 2004. Eurocratising enlargement? EU elites and NGO participation in European environmental policy. Environmental Politics, 13 (1), 175-193.

Helford, R.M., 2000. Constructing nature as constructing science: expertise, activitst science, and public conflict in Chicago wilderness. In: P.H. Gobster and R.B. Hull, eds. Restoring nature: perspectives from the social sciences and humanities. Washington, DC: Island Press, 119-142.

Higgs, E.S., 1997. What is good ecological restoration?. Conservation Biology, 11 (2), $338-348$.

Higgs, E., 2003. Nature by design: people, natural processes and ecological restoration. Boston, MA: MIT Press.

Jordan, W.R. 1994. Sunflower Forest: Ecological Restoration as the Basis for a New Environmental Paragigm. In: A. D. Baldwin, J. DeLuce, and C. Pletsch, eds. Beyond Preservation: restoring and inventing landscapes. Minneapolis: University of Minnesota Press.

Jordan, W.R., 2000. Restoration, community, and wilderness. In: P.H. Gobster and R.B. Hull, eds. Restoring nature: perspectives from the social sciences and humanities. Washington, DC: Island Press, 21-36.

Katz, E., 2000. Another look at restoration: technology and artificial nature. In: P.H. Gobster and R.B. Hull, eds. Restoring nature: perspectives from the social sciences and humanities. Washington, DC: Island Press, 37-48.

Kemp, R. and Parto, S., 2005. Governance for sustainable development: moving from theory to practice. International Journal of Sustainable Development, 8 (1/2), 12-30.

Keulartz, J., 2007. Using metaphors in restoring nature. Nature and Culture, 2 (1), 27-48.

Keulartz, J., 2009. European nature conservation and restoration policy - problems and perspectives. Restoration Ecology, 17 (4), 446-450.

Keulartz, J. and van der Weele, C., 2008. Framing and reframing in invasion biology. Configurations, 16 (1), 93-118.

Krämer, L., 2002. Development of environmental policy in the United States or Europe: convergence or divergence? EUI Florence, Robert Schuman Centre, Paper 2002/33.

Lejon, A., Malm Renöfält, B., and Nilsson, C., 2009. Conflicts associated with dam removal in Sweden. Ecology and Society, 14 (2), 4 [online]. Available from: http:// www.ecologyandsociety.org/vol14/iss $2 /$ art $4 /$.

Light, A. and Higgs, E.S., 1996. The politics of ecological restoration. Environmental Ethics, 18, 227-247.

Lowe, P., Whitman, G., and Phillipson, J., 2009. Ecology and the social sciences. Journal of Applied Ecology, 46, 297-305.

Martinez, M. and Lopez-Barrera, F., 2008. Special issue: restoring and designing ecosystems for a crowded planet. Ecoscience, 15, 1-5. 
McGillivray, D., 2012. Compensating biodiversity loss: The EU commissions' approach to compensation under article 6 of the habitats directive. Journal of Environmental Law, 24 (3), 417-450.

Meadowcroft, J., 2009. What about the politics? Sustainable development, transition management, and long term energy transitions. Policy Sciences, 42 (4), 323-340.

Nellemann, C. and Corcoran, E., eds., 2010. Dead planet, living planet-biodiversity and ecosystem restoration for sustainable development. A rapid response assessment. Nairobi: United Nations Environment Programme.

Palmer, M., et al., 2004. Ecology for a crowded planet. Science, 304, 1251-1252.

Pincock, S., 2010. Plan to save Australian river system runs aground. Nature, 468, 744.

Platt, R.H., 2006. The humane metropolis: people and nature in the $21^{\text {st }}$ century city. Amherst, MA: University of Massachusetts.

Robertson, M.M., 2000. No net loss; wetland restoration and the incomplete capitalisation of nature. Antipode, 32 (4), 463-493.

Ryan, R.L., 2000. A people-centred approach to designing and managing restoration projects: insights from understanding attachment to urban natural areas. In: P.H. Gobster and R.B. Hull, eds. Restoring nature: perspectives from the social sciences and humanities. Washington, DC: Island Press, 208-228.

Salzman, J.E. and Ruhl, J.B., 2005. 'No Net Loss' - instrument choice in wetlands protection. In: J. Freeman and C. Kolstad, eds. Moving to markets in environmental regulation: twenty years of experience. Oxford University Press, Duke Science, Technology \& Innovation Paper No. 1. Available from SSRN: http://ssrn.com/ abstract=796771 [Accessed 14 June 2012].

Schmidt, V., 2010. Taking ideas and discourse seriously: explaining change through discursive institutionalism as the fourth 'new institutionalism'. European Political Science Review, 2 (10), 1-25.

SER, 2004. The SER international primer on ecological restoration. Society for Ecological Restoration International, (Version 2, October, 2004). Available from: http://www.ser.org/content/ecological_restoration_primer.asp [Accessed 14 June 2014].

Stickler, C.M., Nepstad, D.C., and Coe, M.T., 2009. The potential ecological costs and cobenefits of REDD: a critical review and case study from the Amazon region. Global Change Biology, 15, 2803-2824.

Swart, J., van der Windt, H.J., and Keulartz, J., 2001. Valuation of nature in conservation and restoration. Restoration Ecology, 9 (2), 230-238.

Thomspson, A. and Benik-Keymer, J., eds., 2012. Ethical adaptation to climate change: human virtues of the future. Cambridge, MA: MIT Press.

Van der Heijden, H.A., 2005. Ecological restoration, environmentalism and the Dutch politics of "new nature". Environmental Values, 14 (4), 427-446.

Vindel River Life, 2010. Project management plan. Umeå University, Fishery Advisory Board, Swedish University of Agricultural Science, Umeå, Sweden (November).

Vining, J., Taylor, E., and Byoung-Suk, K., 2000. Public values, opinions and emotions in restoration controversies. In: P.H. Gobster and R.B. Hull, eds. Restoring nature: perspectives from the social sciences and humanities. Washington, DC: Island Press, 143-162.

Westphal, L.M., Gobster, P.H., and Gross, M., 2010. Models for renaturing brownfield areas. In: M. Hall, ed. Restoration and history - the search for a usable environmental past. New York: Routledge, 208-217. 